\title{
AN EXAMPLE OF ENERGY DISSIPATION OPTIMIZATION FOR STEEL MRFS WITH PIN-JOINTED COLUMN BASES
}

\author{
Elide Nastri ${ }^{1}$, Annabella Paciello ${ }^{1}$ \\ ${ }^{1}$ University of Salerno \\ Via Giovanni Paolo II, 132, 84084, Fisciano (SA), Italy \\ e-mail: enastri@unisa.it, annabella.paciello@gmail.com
}

Keywords: MRFs, Dissipation optimization, steel, dissipative devices, free from damage structures, Theory of Plastic Mechanism Control.

\begin{abstract}
The proposed work has the aim to show a practical application of the Theory of Plastic Mechanism Control applied to Moment Resisting Frames with pin-jointed base connections whose traditional dissipative zones, i.e. beam ends, in the framework of supplementary energy dissipation strategies, are substituted by frictional devices. The control of devices activation and, as a consequence, the optimization of energy dissipation capacity is obtained by a rigorous design procedure assuring that only the dissipative zones are involved in plastic range while non dissipative ones remain elastic. It means that a mechanism of global type has to be assured by applying the Theory of Plastic Mechanism Control. In addition, being traditional dissipative zones substituted by frictional devices, column bases pin jointed and column sections designed in order to remain in elastic range by a properly design procedure, the structure can be considered as free from damage. In fact after a destructive seismic event all the damaged devices can be replaced by new ones. The accuracy of the design approach has been investigated by means push-over and non-linear dynamic analyses by applying a properly chosen set of earthquake ground motions.
\end{abstract}




\section{INTRODUCTION}

The optimization of seismic energy dissipation has ever been one of the main purposes that has to be fulfilled in order to design structures able to withstand severe earthquake event. For this reason modern seismic codes have introduced simplified rules, such as the beam-column hierarchy criterion having the scope to promote the developing of plastic hinges at the beam ends constituting the dissipative zone, while non dissipative ones, i.e. columns, remain in elastic range [1]. However, this criterion that is reported also in the European seismic code (Eurocode 8 (EC8)) [2] is only able to assure that structures do not collapse with a soft-storey mechanism but it is not able to assure a determinate collapse mode and also a dissipation optimization of the seismic response of the structure. In fact, the seismic response of the structure, and in this case of steel Moment Resisting Frames (MRFs), happens when all the beam ends are engaged in yielding as well as the column bases at first storey. This mode of collapse is called global type.

The development of a collapse mechanism of global type is assured only by a revolutionary design procedure based on the Theory of Plastic Mechanism Control (TPMC) [3] that, differently by the rules proposed by EC8 allows designing structure always showing at the collapse a mechanism of global type. This result is assured thanks both to the strong background of the theory, that is based on the kinematic theorem of plastic collapse, than to the successive improvements of the design procedure that have led to a recent version that is easy to be carried out by means of hand calculation. This last form of the design procedure is the so called "closed form solution of TPMC" that has been satisfactorily applied to design both MRFs [4] than EBF-MRFs dual systems [5]. However, this procedure, in the previous but as the same efficient form as the improved one, has been applied to design all the structural steel typology [6] - [21] and also reinforced concrete MRFs [22]-[23].

Even though, this procedure is able to assure a collapse mechanism of global type, the seismic optimization has to be pursued by assuring that all the dissipative zones engage in yielding as possible as the same time. For this reason, in this structural example, with the scope to have a supplementary and substitutive dissipation [24]-[28], traditional dissipative zones, such as the beam ends, have been substituted by innovative frictional devices [29] developed in the framework of the European Research Project "FREEDAM". As a consequence, the design procedure based on TPMC has improved to promote the contemporary activation of all dissipative devices by additionally considering the column bases at the first storey pinned. In this way, being only the device activated, column bases pin jointed and column sections designed in order to remain in elastic range by a properly design procedure, the structure can be considered as free from damage [30]-[31]. In fact after a destructive seismic event all the damaged devices can be replaced by new ones. The accuracy of the design approach has been investigated by means push-over and non-linear dynamic analyses by applying a properly chosen set of earthquake ground motions.

\section{DESIGN APPROACH}

The "Theory of Plastic Mechanism Control" design approach has the aim to provide structures able to fail with a collapse mechanism of global type. Global mechanism represents the optimum in term of structural dissipation capacity being all the dissipative zones involved in the pattern of yielding while the non dissipative ones remain in elastic range. Dissipative zones of traditional MR-Frame are the beam ends and the bases of the column at the first storey. However, in this particular case, beam ends are substituted by special dissipative devices and column bases at the bottom of the first storey by means of pin connections. In this way MRFs plastic hinges cannot develop at the bottom of the first storey columns, so that, only the 
beam ends are involved in plastic range. In order to design members to fulfil this design goal both devices at the beam ends and column sections have to be designed in order to assure on one hand the optimization of the seismic response and from the other hand a collapse mechanism of global type. Both dissipative zone and non-dissipative ones have been designed according to TPMC. The first design unknown having to be provided are the devices at the beam-to-column connections for which, the whole sum of design slip moment has to be provided by assuring that, according with the kinematic theorem of plastic collapse extended to the concept of mechanism equilibrium curve, the collapse multiplier $\alpha$ of the seismic storey forces $F_{k}$ has to be at least equal to 1 at a design displacement $\delta_{u}$ compatible with the ductility supply of dissipative zone:

$$
\alpha=\alpha_{0}^{(g)}-\gamma^{(g)} \delta_{u} \geq 1 \Rightarrow \frac{M_{f b . E d . n_{s}} \sum_{k=1}^{n_{s}} \beta_{k}}{\sum_{k=1}^{n_{s}} F_{k} h_{k}}-\gamma^{(g)} \delta_{u} \geq 1
$$

where $\alpha_{0}^{(g)}$ is the first order collapse multiplier:

$$
\alpha_{0}^{(\mathrm{g})}=\frac{M_{f b . E d . n_{s}} \sum_{k=1}^{n_{s}} \beta_{k}}{\sum_{k=1}^{n_{s}} F_{k} h_{k}}
$$

and $\gamma^{(\mathrm{g})}$ is the slope of mechanism equilibrium curve accounting for second order effects:

$$
\gamma^{(g)}=\frac{\frac{1}{h_{n s}} \sum_{k=1}^{n_{s}} V_{k} h_{k}}{\sum_{k=1}^{n_{s}} F_{k} h_{k}}
$$

In particular, $\mathrm{V}_{\mathrm{k}}$ and $\mathrm{h}_{\mathrm{k}}$ are the sum of all the vertical loads acting at each storey and the storey height, respectively. By designing dissipative zones proportionally to the storey shear they are assured to be engaged in yielding as contemporary as possible, benefit optimization of the seismic response. In addition, Eq. (1) is quite conservative because it assures that also at the collapse the structure is able to support the storey forces distribution. In addition, the design ultimate displacement has to be dependent on the device stroke, i.e. the ultimate distance the dissipative device is able to tread by slippage. By solving as an equality Eq. (1) it is possible to provide the sum of design slip moments at the last storey, $M_{f b . E d . n_{s}}$ :

$$
M_{\text {fb.Ed.n }} \sum_{k=1}^{n_{s}} \beta_{k}=\left(\gamma^{(g)} \delta_{u}+1\right) \sum_{k=1}^{n_{s}} F_{k} h_{k}
$$

that shared by the term $\beta_{k}=\sum_{i_{m}=k}^{n_{s}} F_{k} / F_{n_{s}}$, [32]-[33] provides the sum of design slip moment at each storey optimized to promote the contemporary engagement in slippage, $M_{f b . E d . k}$ :

$$
M_{f b . E d . k}=\beta_{k} M_{f b . E d . n_{s}}
$$

Finally, $M_{f b . E d . k}$ has to be shared between all the bay in function of the loads $q_{j}$ and the bay length $L_{j}$ :

$$
M_{f b . E d . j k}=M_{f b . E d . k} \frac{q_{j} L_{j}^{2}}{2 \sum_{j=1}^{n_{b}} q_{j} L_{j}^{2}}
$$

The design slip moment $M_{f b . E d . j k}$ is used to design frictional devices whose resistance is expressed by means of the following term $M_{f b . c d . j k}$.

Beams, in this case, have to be considered as non dissipative zones and to be designed by means as the maximum among the design moment belonging to the vertical load distribution and, according to the second capacity design principle, those provided by a local hierarchy criterion where $\gamma_{R d}$ is an overstrength factor. 


$$
M_{b . C d . j k}=\max \left(\frac{q_{v . j} L_{j}^{2}}{8} ; \gamma_{R d} M_{f b . C d . j k}\right)
$$

As regards the column design, all the possible mechanism typology which can affect a seismic resistant frame should be considered. In particular, it is possible to observe that MRFs under seismic horizontal forces should fail according to three main collapse typologies called type-1, type-2 and type-3, as reported in

Figure 1 for the specific case of pin-jointed column bases where the rectangles represents the dissipative devices involved while the solid circles the plastic hinges developing at the top or bottom end of columns for undesired mechanisms. Every one of these can involve each storey and, for this reason, being the number of storey equal to $n_{s}$ the number of possible mechanisms involving a structure can be easily computed as $3 n_{s}$. Only one of these mechanisms is the desired one, i.e. the global one, and it is a particular case of type- 2 mechanism extended to all the $n_{s}$ storeys. It means that all the other $3 n_{s}-1$ mechanisms are undesired and must be avoid by applying TPMC.

The design conditions also found their theoretical bases in the kinematic theorem of plastic collapse extended to the concept of collapse mechanism equilibrium curve which is representative of a straight line whose intercept with the vertical axis in a Cartesian diagram is the collapse mechanism multiplier of the first order, $\alpha_{i_{m}}^{(t)}$, while $\gamma_{i_{m}}^{(t)}$ is the slope where $i_{m}$ and $t$ are the mechanism index and the mechanism typology code respectively.
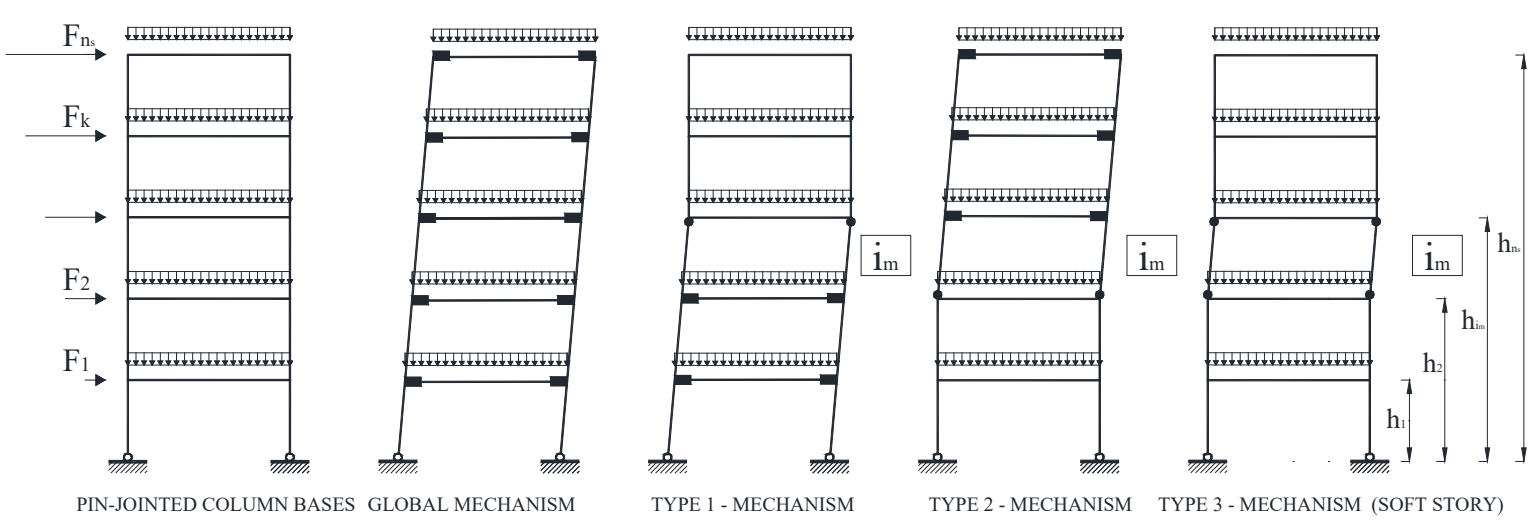

Figure 1: Collapse mechanism of pin-jointed column bases resistant frame

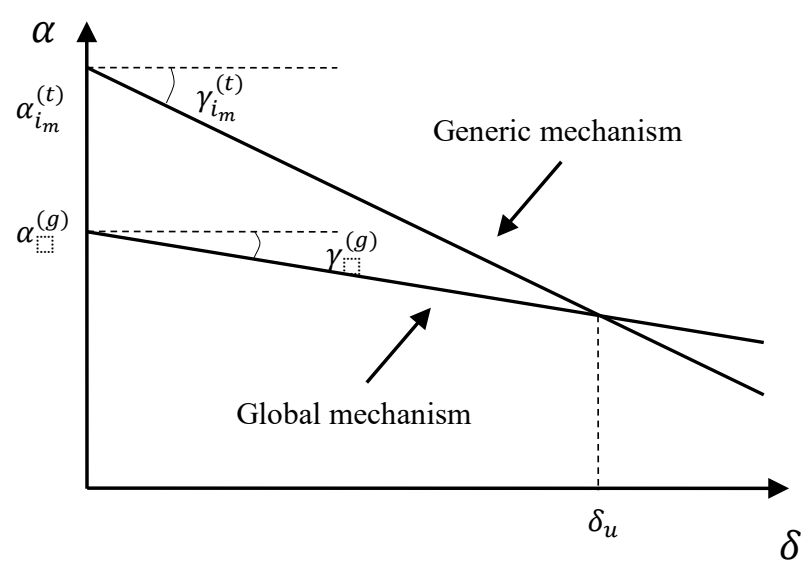

Figure 2: Design condition for the failure mode control 
TPMC states that the global mechanism equilibrium curve has to be located below those corresponding to all the other mechanisms within a displacement range compatible with the plastic deformation capacity of members, $\delta_{\mathrm{u}}$ (Figure 2 ). Consequently, the design conditions are provided by the following equations:

$$
\alpha^{(g)}-\gamma^{(g)} \delta_{u} \leq \alpha_{i_{m}}^{(t)}-\gamma_{i_{m}}^{(t)} \delta_{u} \quad i_{m}=1,2,3, \ldots, n_{s} \quad t=1,2,3
$$

The computation of the quantities $\alpha_{i_{m}}^{(t)}$ and $\gamma_{i_{m}}^{(t)}$ exploits the virtual work principle and it is amply detailed and discussed in a previous work [3]-[4]. In particular, the expressions of $\alpha_{i_{m}}^{(t)}$ and $\gamma_{i_{m}}^{(t)}$ are reported in Table 1 . In particular, according to the second capacity design principle, non dissipative zones have to be designed according to the maximum actions that dissipative zones, i.e. dissipative devices, are able to transmit in their ultimate conditions. For this reason, frictional device overstrength have to be considered by introducing the overstrength factor $\gamma_{R d}$.

$$
\begin{array}{lcc}
\hline \text { Type-1 } & \text { Type-2 } & \text { Type-3 } \\
\hline \alpha_{0 . i_{m}}^{(1)}=\gamma_{R d} \frac{M_{f b . c d . n_{s}} \sum_{k=1}^{i_{m}-1} \beta_{k}+\sum_{i=1}^{n_{c}} M_{c . i_{m}}^{(1)}}{\sum_{k=1}^{i_{m}} F_{k} h_{k}+h_{i_{m}} \sum_{k=i_{m}+1}^{n_{S}} F_{k}} & \alpha_{0 . i_{m}}^{(2)}=\frac{\sum_{i=1}^{n_{c}} M_{c . i_{m}}^{(2)}+\gamma_{R d} M_{f b . c d . n_{s}} \sum_{k=i_{m}}^{n_{s}} \beta_{k}}{\sum_{k=i_{m}}^{n_{s}} F_{k}\left(h_{k}-h_{i_{m}-1}\right)} \alpha_{0 . i_{m}}^{(3)}=\frac{2 \sum_{i=1}^{n_{c}} M_{c . i i_{m}}^{(3)}}{\left(h_{i_{m}}-h_{i_{m}-1}\right) \sum_{k=i_{m}}^{n_{s}} F_{k}} \\
\gamma_{i_{m}}^{(1)}=\frac{\sum_{k=1}^{i_{m}} V_{k} h_{k}+h_{i_{m}} \sum_{k=i_{m}+1}^{n_{S}} V_{k}}{h_{i_{m}}\left(\sum_{k=1}^{i_{m}} F_{k} h_{k}+h_{i_{m}} \sum_{k=i_{m}+1}^{n_{s}} F_{k}\right)} \gamma_{i_{m}}^{(2)}=\frac{\sum_{k=i_{m}}^{n_{s}} V_{k}\left(h_{k}-h_{i_{m}-1}\right)}{\left(h_{n_{s}}-h_{i_{m}-1}\right) \sum_{k=i_{m}}^{n_{s}} F_{k}\left(h_{k}-h_{i_{m}-1}\right)} \gamma_{i_{m}}^{(3)}=\frac{\sum_{k=i_{m}}^{n_{s}} V_{k}}{\left(h_{i_{m}}-h_{i_{m}-1}\right) \sum_{k=i_{m}}^{n_{s}} F_{k}}
\end{array}
$$

Table 1. First order and second order collapse mechanism multiplier at the generic $\mathrm{i}_{\mathrm{m}}-$ th storey

Therfore, by substituting terms reported in Table 1 in Eq. (8), the following design relationship are obtained for type-1 mechanism:

$$
\gamma_{R d} \frac{M_{f b . C d . n_{s}} \sum_{k=1}^{n_{s}} \beta_{k}}{\sum_{k=1}^{n_{s}} F_{k} h_{k}}-\gamma^{(g)} \delta_{u} \leq \frac{M_{f b . C d . n_{s}} \sum_{k=1}^{i_{m}-1} \beta_{k}+\sum_{i=1}^{n_{c}} M_{c . i i_{m}}^{(1)}}{\sum_{k=1}^{i_{m}} F_{k} h_{k}+h_{i_{m}} \sum_{k=i_{m}+1}^{n_{s}} F_{k}}-\gamma_{i_{m}}^{(1)} \delta_{u}
$$

for type-2 mechanism:

$$
\gamma_{R d} \frac{M_{f b . C d . n_{s}} \sum_{k=1}^{n_{s}} \beta_{k}}{\sum_{k=1}^{n_{s}} F_{k} h_{k}}-\gamma^{(g)} \delta_{u} \leq \frac{\sum_{i=1}^{n_{c}} M_{c . i i_{m}}^{(2)}+\gamma_{R d} M_{f b . c d . n_{s}} \sum_{k=i_{m}}^{n_{s}} \beta_{k}}{\sum_{k=i_{m}}^{n_{s}} F_{k}\left(h_{k}-h_{i_{m}-1}\right)}-\gamma_{i_{m}}^{(2)} \delta_{u}
$$

and for type-3 mechanism :

$$
\begin{gathered}
\text { for } i_{m}=1 \quad \gamma_{R d} \frac{M_{f b . c d . n_{s}} \sum_{k=1}^{n_{s}} \beta_{k}}{\sum_{k=1}^{n_{s}} F_{k} h_{k}}-\gamma^{(g)} \delta_{u} \leq \frac{\sum_{i=1}^{n_{c}} M_{c . i 1}^{(3)}}{h_{1} \sum_{k=1}^{n_{s}} F_{k}}-\gamma_{1}^{(3)} \delta_{u} \\
\text { for } i_{m}>1 \quad \gamma_{R d} \frac{M_{f b . c d . n_{s}} \sum_{k=1}^{n_{s}} \beta_{k}}{\sum_{k=1}^{n_{s}} F_{k} h_{k}}-\gamma^{(g)} \delta_{u} \leq \frac{2 \sum_{i=1}^{n_{c}} M_{c . i i_{m}}^{(3)}}{\left(h_{i_{m}}-h_{i_{m}-1}\right) \sum_{k=i_{m}}^{n_{s}} F_{k}}-\gamma_{i_{m}}^{(3)} \delta_{u}
\end{gathered}
$$

That rearranged to provide the unknown of the design procedure, i.e. the sum of column plastic moment at each storey $M_{c . i i_{m}}^{(t)}$ reported in the following.

In particular, at the first storey the condition reported in Eq. (8) provide only one design relationship being easily demonstrable that mechanism type- 1 and type- 3 at the first storey are coincident and mechanism type-2 is coincident with the global one: 


$$
\sum_{i=1}^{n_{c}} M_{c . i 1}^{(10 r 3)} \geq\left[\gamma_{R d} \frac{M_{f b . E d . n_{s}} \sum_{k=1}^{n_{s}} \beta_{k}}{\sum_{k=1}^{n_{s}} F_{k} h_{k}}+\left(\gamma_{1}^{(3)}-\gamma^{(g)}\right) \delta_{u}\right]\left(h_{i_{m}}-h_{i_{m}-1}\right) \sum_{k=i_{m}}^{n_{s}} F_{k}
$$

At the $i_{m}>1$ storeys, design conditions have to be make explicit for all the undesired mechanism typologies:

for type-1 mechanism;

$$
\begin{array}{r}
\sum_{i=1}^{n_{c}} M_{c . i i_{m}}^{(1)} \geq\left[\gamma_{R d} M_{f b . c d . n_{s}}\left(\frac{\sum_{k=1}^{n_{s}} \beta_{k}}{\sum_{k=1}^{n_{s}} F_{k} h_{k}}-\frac{\sum_{k=1}^{i_{m}-1} \beta_{k}}{\sum_{k=1}^{i_{m}} F_{k} h_{k}+h_{i_{m}} \sum_{k=i_{m}+1}^{n_{s}} F_{k}}\right)\right. \\
\left.+\left(\gamma_{i_{m}}^{(1)}-\gamma^{(g)}\right) \delta_{u}\right]\left(\sum_{k=1}^{i_{m}} F_{k} h_{k}+h_{i_{m}} \sum_{k=i_{m}+1}^{n_{s}} F_{k}\right)
\end{array}
$$

$$
\sum_{i=1}^{n_{c}} M_{c . i i_{m}}^{(2.1)} \geq\left[\gamma_{R d} M_{f b . c d . n_{s}}\left(\frac{\sum_{k=1}^{n_{S}} \beta_{k}}{\sum_{k=1}^{n_{S}} F_{k} h_{k}}-\frac{\sum_{k=i_{m}}^{n_{S}} \beta_{k}}{\sum_{k=i_{m}}^{n_{S}} F_{k}\left(h_{k}-h_{i_{m}-1}\right)}\right)+\left(\gamma_{i_{m}}^{(2)}-\gamma^{(g)}\right) \delta_{u}\right] \sum_{k=1}^{i_{m}} F_{k}\left(h_{k}-h_{i_{m}-1}\right)
$$

for type-2 mechanism;

$$
\sum_{i=1}^{n_{c}} M_{c . i i_{m}}^{(3)} \geq\left[\gamma_{R d} M_{f b . c d . n_{s}} \frac{\sum_{k=1}^{n_{s}} \beta_{k}}{\sum_{k=1}^{n_{s}} F_{k} h_{k}}+\left(\gamma_{1}^{(3)}-\gamma^{(g)}\right) \delta_{u}\right] \frac{\left(h_{i_{m}}-h_{i_{m}-1}\right)}{2} \sum_{k=i_{m}}^{n_{s}} F_{k}
$$

for type-3 mechanism.

While for the $i_{m}=1$ storey the design condition is only one Eq. (13) for the $i_{m}>1$ storeys, the sum of the reduced plastic moments of columns has to be calculated as the maximum among the three mechanism typologies, according to the following relation:

$$
\sum_{i=1}^{n_{c}} M_{c . i i_{m}}=\max \left\{\sum_{i=1}^{n_{c}} M_{c . i i_{m}}^{(1)}, \sum_{i=1}^{n_{c}} M_{c . i i_{m}}^{(2)}, \sum_{i=1}^{n_{c}} M_{c . i i_{m}}^{(3)}\right\}
$$

The knowledge of these plastic moments, coupled with the estimated axial force at the collapse state, allows the evaluation of the required sections of columns.

The sum provided by Eq. (16) has to be distributed between all the columns at each storey according to two possible strategies [4]:

1) the sum are subdivided equally between each column

2) the sum are subdivided according to the axial load acting on the columns in the collapse condition.

However, in both the cases column sections need to verify the combination of the competent axial load at collapse and bending moment.

The axial load acting on the columns at collapse state can be easily provided in agreement with the global mechanism where axial forces in the columns at collapse state depend both on distributed loads acting on the beams and on the shear action coming from the development of plastic hinges at the beam ends, as depicted in Figure 3. So that, the total load transmitted by the beams to the columns is the sum of two contributions. The first one, $\mathrm{N}_{\mathrm{q}}$, is related to the vertical loads acting in the seismic load combination (i.e. the sum of $\mathrm{qL}_{\mathrm{j}} / 2$ type contributions). The second one, $\mathrm{N}_{\mathrm{f}}$, is related to the shear actions due to the engagement in plastic range of the dissipative devices located at the beam ends (i.e. the sum of $2 \gamma_{\mathrm{Rd}} \mathrm{M}_{\mathrm{fb} . \mathrm{Cd} . \mathrm{n}_{\mathrm{s}}} / \mathrm{L}_{\mathrm{j}}$ contributions) (Figure 3). Also in this case, devices overstrength has to be taken in account according to the second capacity design principle. However, seismic actions can be acting either in the 
positive direction or in the negative direction, so that the maximum axial forces has to be considered.

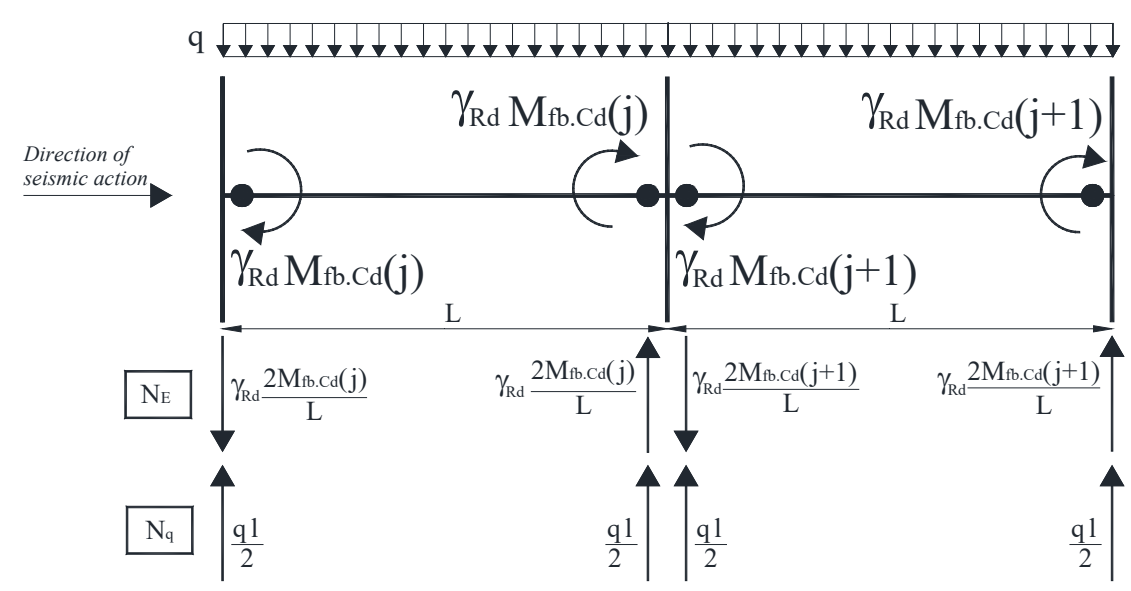

Figure 3: Loads transmitted by the beams to the columns at collapse state including the overstrength of the device

\section{WORKED EXAMPLE}

Aiming to practically show how to apply the proposed design procedure a 3 bays 4 storeys pin-jointed column bases structure whose structural scheme is depicted in Figure 4 has been designed. The bay span is $5 \mathrm{~m}$ while the interstorey height is equal to $3.0 \mathrm{~m}$. The characteristic values of the vertical loads acting on beams are equal to $6,68 \mathrm{kN} / \mathrm{m}^{2}$ and $5,01 \mathrm{kN} / \mathrm{m}^{2}$ for permanent and live loads, respectively, while on columns concentrated loads belonging to the secondary warping of floor are applied (Figure 4). With reference to the seismic load combination $\left(\mathrm{G}_{\mathrm{k}}+\Psi_{2} \mathrm{Q}_{\mathrm{k}}+\mathrm{E}_{\mathrm{d}}\right)$, the vertical loads acting on the beams of the analysed structure are $8,183 \mathrm{kN} / \mathrm{m}$. The structural material adopted for all the structural members is an S275. The design horizontal forces have been determined according to EC8, assuming a peak ground acceleration equal to $0.20 \mathrm{~g}$, a seismic response factor equal to 2.5 , a behaviour factor equal to 6 . The design horizontal forces distribution is in accord to the first vibration mode as reported in Figure 4.

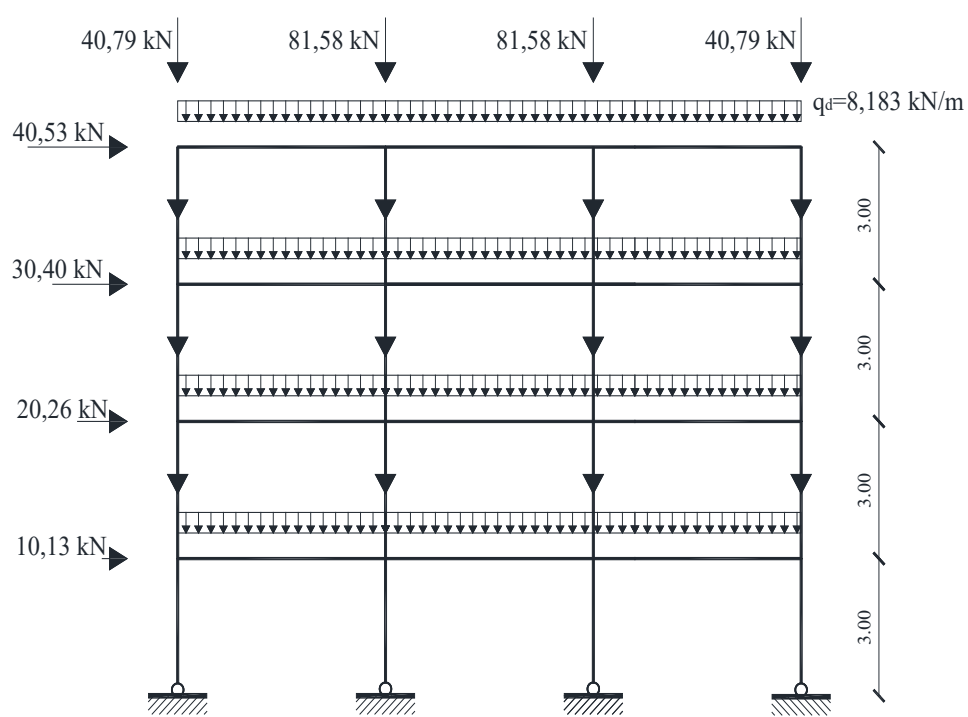

Figure 4: Worked example structural scheme 
Beam-to-column devices (Figure 5) are bolted double split tee beam-to-column connections equipped with friction dampers designed to slip before the yielding of the beam [34] where the energy is dissipated through the slippage between the stem of bolted tee stubs and the beam flange with an interposed friction pad. Adopted bolts are high resistance class 8.8 while the friction material adopted (FREEDAM project) is sprayed aluminum that is able to exhibit a friction coefficient of about 0.5 [35].

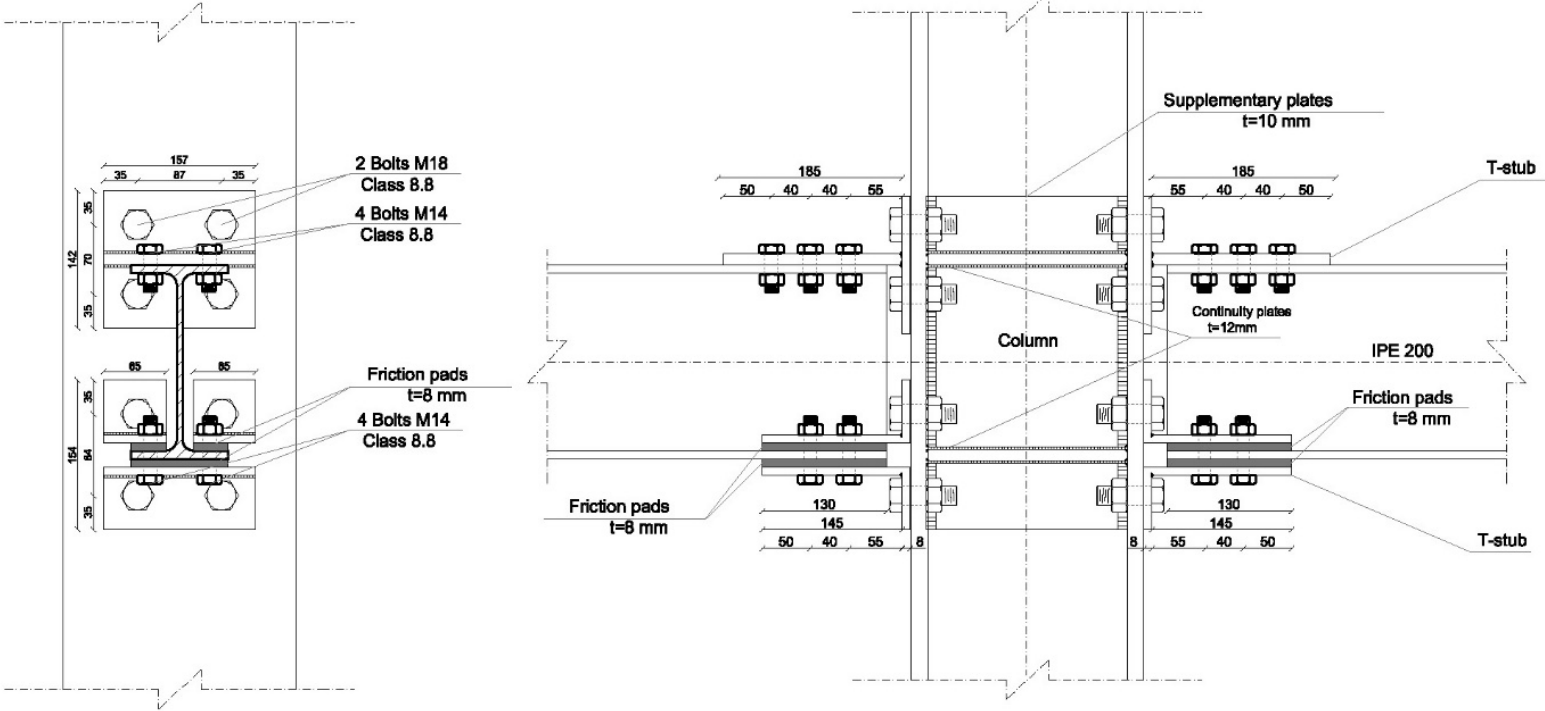

Figure 5: Beam to column connections equipped with friction dampers

\subsection{Design of dissipative zones}

The first quantity needed for the design of the structure is the design slip moment of devices at the last storey (storey $n_{s}$ ) provided by Eq. (4), being preliminarily compute the term $\sum_{k=1}^{n_{s}} \beta_{k}=7,5$. Successively, the sum of the design slip moment $M_{f b . E d . n_{s}}$ has to be shared between all the storeys by means of the term $\beta_{k}$ to design the dissipative device preliminarily described, according to the following relation:

$$
M_{f b . E d . n_{s}}=n_{s} n_{b} N_{b} \mu h_{b} \rightarrow M_{f b . C d . n_{s}}
$$

where, $n_{s}$ is the number of frictional surfaces that in this case is equal to $2, n_{b}$ is number of bolts, $N_{b}$ is the preloading force equal to:

$$
N_{b}=0.7 f_{u b} A_{s}
$$

$f_{u b}$ is the design bolt resistance, $A_{s}$ is the bolt area, $\mu$ is the dynamic frictional coefficient assumed in this case equal to 0.5 and $h_{b}$ is the beam height preliminarily assumed equal to the height of the beam designed by means of vertical load combination. In this case, beams are preliminarily selected from the standard shapes to withstand the vertical load combination $\left(1.3 G_{k}+1.5 Q_{k}\right)$ according to a design moment computed as in Eq. (7) and are IPE200. In addition, in Table 2 the sum of the design slip moment $M_{f b . E d . k}$ shared at all the storey by means of the term $\beta_{k}$, the slip resistant moment $M_{f b . C d . k}$, belonging to the device design, the number of bolts $n_{b}$, the beam height, the preloading force $N_{b}$ are reported.

Finally, beam sections designed to withstand vertical loads have to fulfil also the local hierarchy criterion reported in the second term of Eq. (7). 


\begin{tabular}{ccccccccc}
\hline $\begin{array}{c}\text { Storey } \\
(-)\end{array}$ & $\beta_{k}$ & $\begin{array}{c}M_{f b . E d . k} \\
(-)\end{array}$ & $\begin{array}{c}n_{b} \\
(k N m)\end{array}$ & $\begin{array}{c}h_{b} \\
(-)\end{array}$ & $\begin{array}{c}\text { Bolts } \\
(-)\end{array}$ & $\begin{array}{c}N_{b} \\
k N\end{array}$ & $\begin{array}{c}M_{f b . C d . k} \\
(k N m)\end{array}$ & $\begin{array}{c}\gamma_{R d} M_{f b . C d . k} \\
(k N m)\end{array}$ \\
\hline 1 & 2.5 & 451.00 & 4 & 200 & $\phi 18$ & 120.00 & 460.80 & 552.96 \\
2 & 2.25 & 405.90 & 4 & 200 & $\phi 18$ & 110.00 & 422.40 & 506.88 \\
3 & 1.75 & 315.70 & 4 & 200 & $\phi 18$ & 850.00 & 326.40 & 391.68 \\
4 & 1 & 180.40 & 4 & 200 & $\phi 18$ & 500.00 & 192.00 & 230.40 \\
\hline
\end{tabular}

Table 2: Parameters for the design of beam-to-column connections

\subsection{Design of non-dissipative zones}

Being designed dissipative zones, also non-dissipative one have to be provided by means of TPMC. The ultimate design displacement governing the procedure has been computed in the following way:

$$
\delta_{u}=0.04 h_{n_{s}}=0.04 \cdot 12=0.48 \mathrm{~m}
$$

being assumed an ultimate device rotation equal to 0.04. In addition, in Table 3 the slopes of mechanism equilibrium curves are reported being computed according to the relationships reported in Table 1.

\begin{tabular}{cccc}
\hline STOREY $\boldsymbol{i}_{\boldsymbol{m}}$ & $\boldsymbol{\gamma}_{\boldsymbol{i}_{\boldsymbol{m}}}^{(\mathbf{1})}(1 / \mathrm{cm})$ & $\boldsymbol{\gamma}_{\boldsymbol{i}_{\boldsymbol{m}}}^{(\mathbf{2})}(1 / \mathrm{cm})$ & $\boldsymbol{\gamma}_{\boldsymbol{i}_{\boldsymbol{m}}}^{(\mathbf{3})}(1 / \mathrm{cm})$ \\
\hline 1 & 0.0484 & $\underline{0.0101}$ & 0.0484 \\
2 & 0.0223 & 0.0121 & 0.0403 \\
3 & 0.0139 & 0.0165 & 0.0345 \\
4 & 0.0101 & 0.0302 & 0.0302 \\
\hline
\end{tabular}

Table 3. Slopes of the mechanism equilibrium curves

It is possible to observe that the slope of the global mechanism equilibrium curve (undersigned in Table 3) is the minimum among all the slope of mechanism equilibrium curves corresponding to the undesired mechanism. In addition, in Table 4 the design bending moment of columns at each storey are reported.

\begin{tabular}{ccccc}
\hline STOREY $\boldsymbol{i}_{\boldsymbol{m}}$ & $\sum_{\boldsymbol{i}=\mathbf{1}}^{\boldsymbol{n}_{\boldsymbol{c}}} \boldsymbol{M}_{\boldsymbol{c} . \boldsymbol{i}_{\boldsymbol{m}}}^{(\mathbf{1}}(\mathrm{kN} \mathrm{m})$ & $\sum_{\boldsymbol{i}=\mathbf{1}}^{\boldsymbol{n}_{\boldsymbol{c}}} \boldsymbol{M}_{\boldsymbol{c} . \boldsymbol{i}_{\boldsymbol{m}}}^{(\boldsymbol{2})}(\mathrm{kN} \mathrm{m})$ & $\sum_{\boldsymbol{i}=\mathbf{1}}^{\boldsymbol{n}_{\boldsymbol{c}}} \boldsymbol{M}_{\boldsymbol{c} . \boldsymbol{i}_{\boldsymbol{m}}}^{(\mathbf{3})}(\mathrm{kN} \mathrm{m})$ & $\sum_{\boldsymbol{i}=\mathbf{1}}^{\boldsymbol{n}_{\boldsymbol{c}}} \boldsymbol{M}_{\boldsymbol{c} . \boldsymbol{i}_{\boldsymbol{m}}}(\mathrm{kN} \mathrm{m})$ \\
\hline 1 & 1119.24 & {$[-]$} & 1119.24 & 1119.24 \\
3 & 850.36 & 51.12 & 450.74 & 850.36 \\
4 & 544.82 & 97.52 & 321.17 & 544.82 \\
& 230.40 & 111.46 & 170.93 & 230.40 \\
\hline
\end{tabular}

Table 4. Value of the paramters $\sum_{\mathrm{i}=1}^{\mathrm{n}_{\mathrm{c}}} \mathrm{M}_{\mathrm{c.ii} \mathrm{m}}^{(\mathrm{t})}$

In this worked example the approach that have been used to subdivide the reduced sum of plastic moments between the columns exploits the axial load acting on the columns at collapse state. In fact, the maximum value of $M_{c, i_{m}}$ is subdivided between columns on the basis of axial force acting on each column at each storey.

The reduced sum of plastic moments of columns at each storey, $\sum_{i=1}^{n_{c}} M_{c . i i_{m}}$, has been subdivided proportionally to the axial load at the collapse state according to the following equation: 


$$
M_{c . i k}=\frac{N_{t o t . i i_{m}} \sum_{i=1}^{n_{c}} M_{c . i i_{m}}}{\sum_{i=1}^{n_{c}} N_{t o t . i i_{m}}}
$$

where $M_{c . i k}$ is the design moment of column sections.

Finally, in Table 5 the axial load acting at the collapse state, the design moment of column sections and the column sections selected from standard shapes are reported with reference to external and internal columns. Finally the collapse mechanism multiplier of global type $\alpha=$ $1,84)$.

\begin{tabular}{ccccccc}
\hline STOREY $i_{m}$ & \multicolumn{3}{c}{ External columns } & \multicolumn{3}{c}{ Internal columns } \\
\hline & $N_{\text {tot. } . i_{m}}(k N)$ & $M_{\text {c.ik }}(\mathrm{kN} \mathrm{m})$ & PROFILES & $N_{\text {tot. } i i_{m}}(k N)$ & $M_{\text {c.ik }}(\mathrm{kN} \mathrm{m})$ & PROFILES \\
1 & 357.12 & 292.20 & HE 240 B & 490.00 & 278.64 & HE 260 B \\
2 & 259.01 & 289.30 & HE 200 B & 367.50 & 275.88 & HE 240 B \\
3 & 163.97 & 249.63 & HE 180 B & 245.00 & 238.05 & HE 200 B \\
4 & 76.61 & 154.81 & HE 140 B & 122.50 & 147.63 & HE 160 B \\
\hline
\end{tabular}

Table 5. Axial force at collapse state, design moment of column sections and column sections selected from standard shapes at each storey

\section{VALIDATION OF PROCEDURE}

In order to validate the design procedure static non linear analysis (push-over) has been carried out for the designed frame by means of SAP 2000 computer program [36]. This analysis has the primary aim to predict the collapse mechanism typology, testing the accuracy of the proposed design methodology.

In SAP2000 ambiance all members have been modeled by means of beam-column elements, whose non-linearities have been concentrated in plastic hinges at their ends. In particular, plastic hinges accounting for the interaction between axial force and bending moment have been defined for columns while dissipative devices at beam ends have been modelled in pure bending. All hinges have been represented with a rigid plastic curve. The elastic behaviour is not considered in plastic hinge definition because it is directly taken into account by the beam-column element. The analysis has been led under displacement control taking into account both geometrical and mechanical non-linearities. In addition out of plan stability check of compressed members have been performed at each step of the non-linear analysis. The results of the push-over are mainly constituted by the frame capacity curve. In Figure 6 the push-over curve is provided with reference to two different structural models, the first one corresponding to the use of a Young modulus (E) equal to $210000 \mathrm{MPa}$ the second one (dotted line) corresponding to a structural model with a ten times increased Young modulus value. This second one is proposed to more accurately point out that the softening branch of pushover curve is perfectly parallel to the global mechanism equilibrium curve. This condition shows this evidence once the structural model is more close to the hypothesis of rigid perfect plastic behavior that is herein obtained by increasing the Young Moduls.

In addition, the designed structure has been checked also for serviceability requirements under seismic action evaluated with a first period of vibration equal to $2,53 \mathrm{~s}$. Beam to column connections have also been checked to be inactive under vertical load combination at the ultimate limit state. 


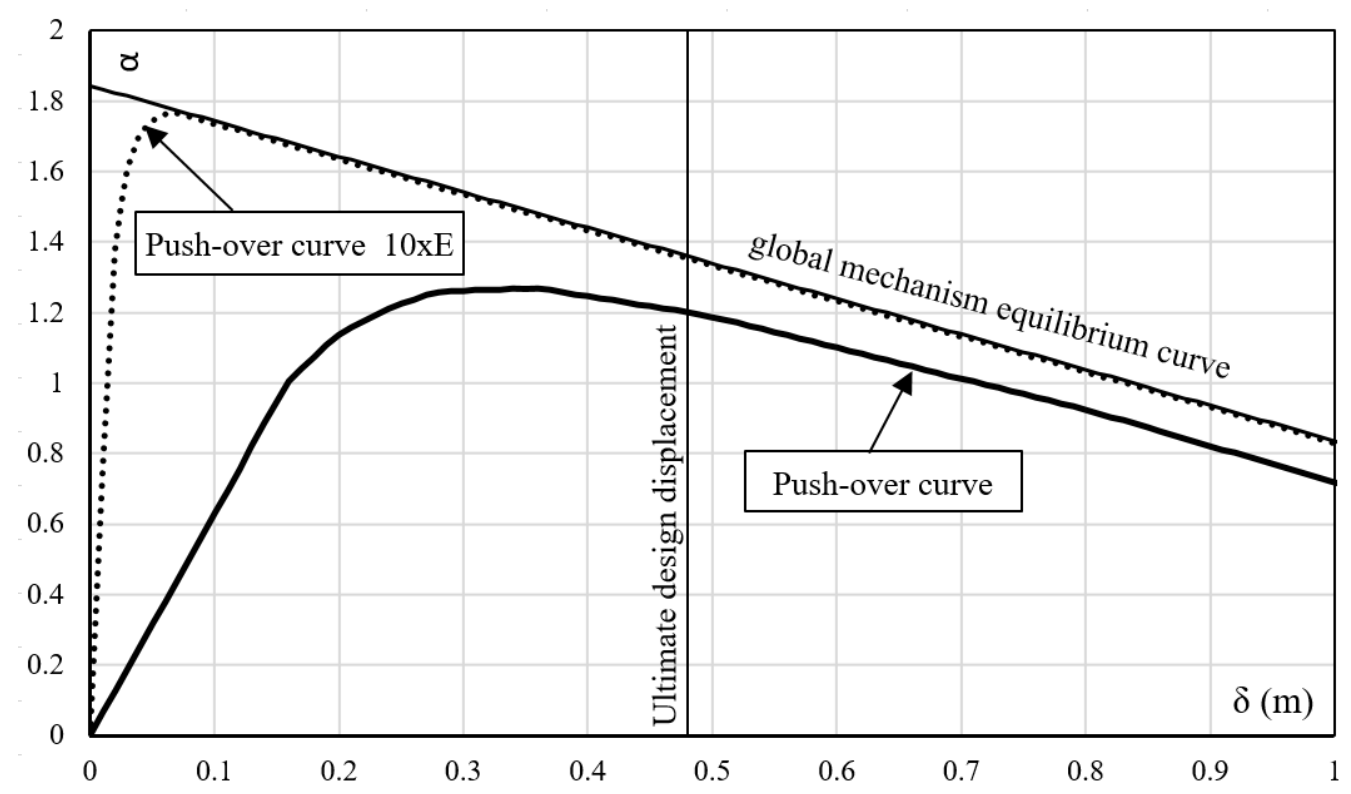

Figure 6: Push-over curves for $\mathrm{E}=210000$ and 10xE

In addition, in order to provide a more robust validation of the design methodology, nonlinear Incremental Dynamic Analyses (IDA) have been carried out with reference to the same structural model used for push-over analyses. In addition, 5\% damping according to Rayleigh modelling has been assumed.

Record-to-record variability has been accounted for considering 10 recorded accelerograms selected from PEER [37] data base whose main characteristics (name, date, magnitude, ratio between PGA and gravity acceleration, length and step recording) are reported in Table 6 . These earthquake records have been selected to approximately match the linear elastic design response spectrum of Eurocode 8 [2], for type A soil. Moreover, in order to perform IDA analyses, each ground motion has been scaled to obtain the same value of the spectral acceleration $\mathrm{Sa}\left(\mathrm{T}_{1}\right)$ corresponding to the fundamental period of vibration $\mathrm{T}_{1}$ of the structure $\left(\mathrm{T}_{1}=2,53 \mathrm{~s}\right)$. This is the seismic intensity measure (IM) adopted for IDA analyses where $\mathrm{Sa}\left(\mathrm{T}_{1}\right)$ values have been progressively increased until the occurrence of structural collapse, corresponding to anyone of the following ultimate limit states: column buckling, complete development of a collapse mechanism, attainment of the limit value of plastic rotation of frictional devices or columns.

\begin{tabular}{cccccc}
\hline Earhquake (record) & Component & Date & PGA/g & Length (s) & Step recording (s) \\
\hline Coalinga (Slack Canyon) & H-SCN045 & $1985 / 05 / 02$ & 0.166 & 29.99 & 0.01 \\
Friuli, Italy (Buia) & B-BUI000 & $1976 / 09 / 15$ & 0.110 & 26.385 & 0.005 \\
Imperial Valley (Agrarias) & H-AGR003 & $1979 / 10 / 15$ & 0.370 & 28.35 & 0.01 \\
Kobe (Kakogawa) & KAK000 & $1995 / 01 / 16$ & 0.251 & 40.95 & 0.01 \\
Northridge (Stone Canyon) & SCR000 & $1994 / 01 / 17$ & 0.252 & 39.99 & 0.01 \\
Santa Barbara (Courthouse) & SBA132 & $1978 / 08 / 13$ & 0.102 & 12.57 & 0.01 \\
Spitak Armenia (Gaukasian) & GKS000 & $1998 / 12 / 07$ & 0.199 & 19.89 & 0.01 \\
Friuli, Italy (Tolmezzo) & TMZ000 & $1976 / 05 / 06$ & 0.351 & 36.345 & 0.005 \\
Irpinia (Calitri) & A-CTR000 & $1980 / 11 / 23$ & 0.132 & 35.79 & 0.0024 \\
Victoria, Mexico (Chihuahua) & CHI102 & $1980 / 06 / 09$ & 0.150 & 26.91 & 0.01 \\
\hline
\end{tabular}




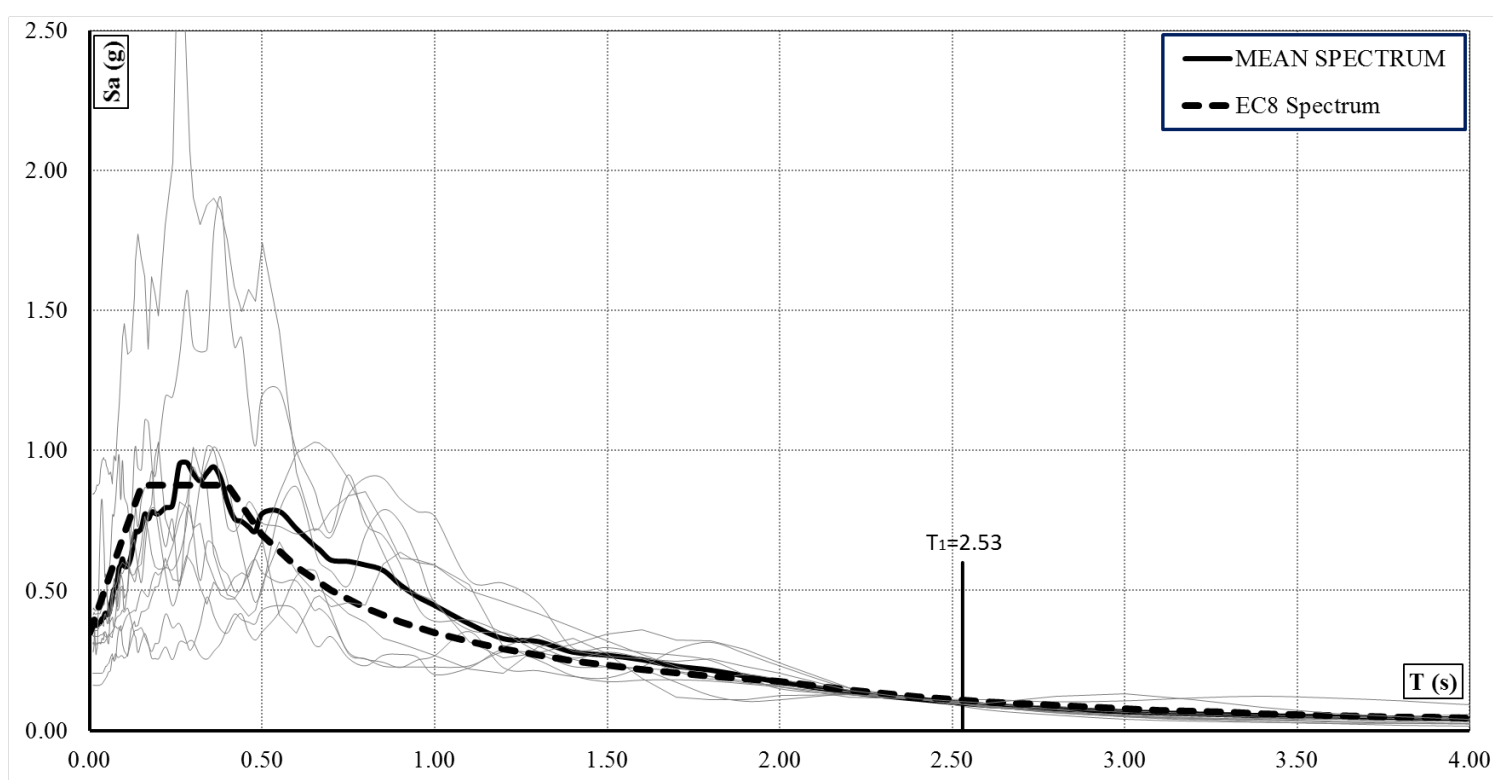

Figure 7: Response spectra (soil type A, $\zeta=5 \%$ ) scale at the same value of $\mathrm{Sa}$ for $\mathrm{T} 1=2,53$

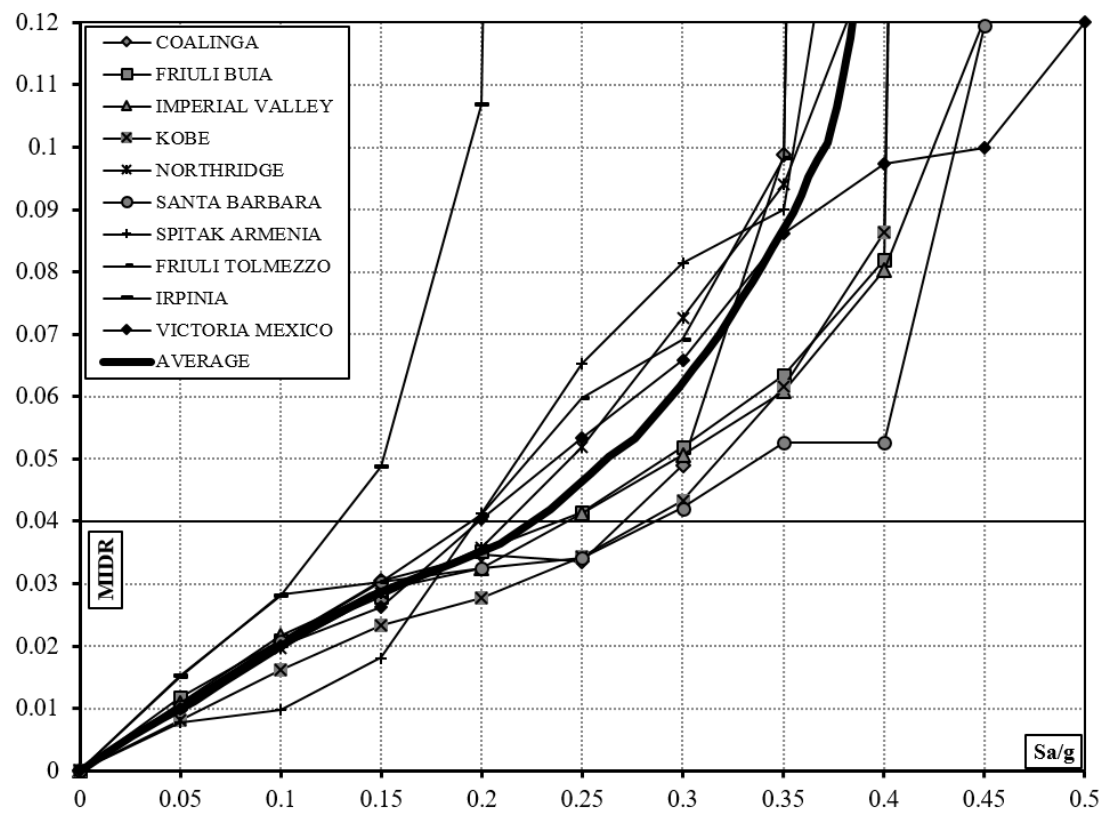

Figure 8: Maximum Interstorey Drift Ratio (MIDR) vs Spectral Acceleration (Sa/g)

In Figure 8 the Maximum Interstorey Drift Ratio (MIDR) vs Spectral Acceleration is reported. MIDR curves appears regular and always increasing reaching on average a spectral acceleration of $0.23 \mathrm{~g}$ corresponding to the achievement of the target drift equal to $0.04 \mathrm{rad}$. In addition, for each accelerogram, the obtained pattern of yielding has been monitored as far as the spectral acceleration increases confirming the development of a global mechanism. 


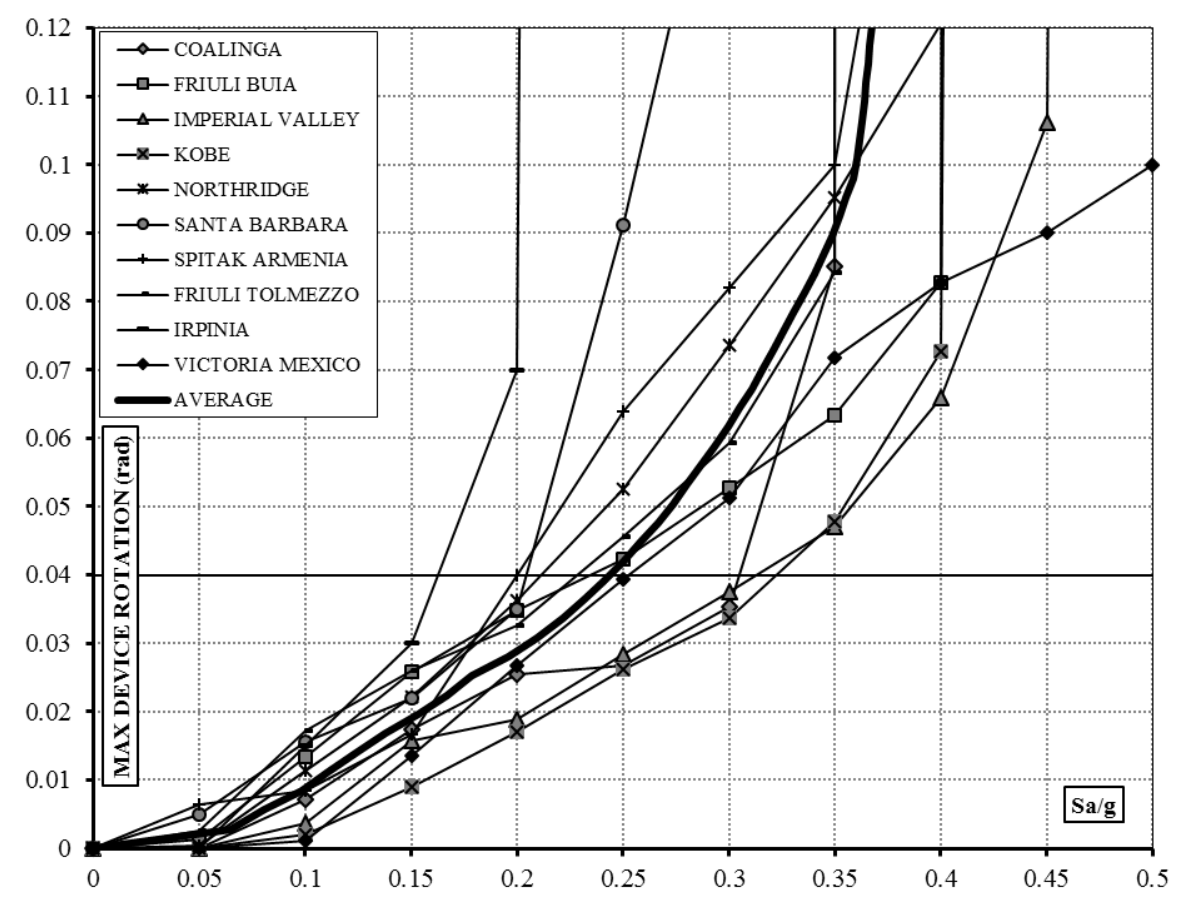

Figure 9: Maximum Device Rotation vs Spectral Acceleration (Sa/g)

In Figure 9 the Maximum Device Rotation vs Spectral Acceleration is reported. In addition, in this case, curves appear regular and increasing.

\begin{tabular}{ccccc}
\hline & MIDR=0.04 rad & \multicolumn{2}{c}{ Collapse } \\
\hline Earhquake (record) & Sa/g & $\mathbf{P G A} / \mathbf{g}$ & Sa/g & PGAc/g \\
Coalinga (Slack Canyon) & 0.30 & 0.832 & 0.32 & 0.888 \\
Friuli, Italy (Buia) & 0.25 & 0.796 & 0.24 & 0.860 \\
Imperial Valley (Agrarias) & 0.25 & 0.617 & 0.32 & 0.790 \\
Kobe (Kakogawa) & 0.30 & 0.804 & 0.32 & 0.991 \\
Northridge (Stone Canyon) & 0.23 & 1.036 & 0.23 & 1.036 \\
Santa Barbara (Courthouse) & 0.30 & 0.900 & 0.20 & 0.600 \\
Spitak Armenia (Gaukasian) & 0.20 & 0.736 & 0.20 & 0.736 \\
Friuli, Italy (Tolmezzo) & 0.20 & 1.500 & 0.23 & 1.725 \\
Irpinia (Calitri) & 0.125 & 0.228 & 0.17 & 0.307 \\
Victoria, Mexico (Chihuahua) & 0.20 & 0.288 & 0.25 & 0.360 \\
Mean value & $\mathbf{0 . 2 3}$ & $\mathbf{0 . 7 7 4}$ & $\mathbf{0 . 2 4 8}$ & $\mathbf{0 . 8 2 9}$ \\
\hline
\end{tabular}

Table 7: $\mathrm{S}_{\mathrm{a}}\left(\mathrm{T}_{1}\right)$ and PGA values corresponding to the attainment of the structural collapse

Finally, for reason of clarity, the spectral acceleration values leading to collapse are given in Table 7 both in term of spectral acceleration $\left(\mathrm{S}_{\mathrm{a}}\right)$ than PGA. In particular, the average value of $\mathrm{S}_{\mathrm{a}}\left(\mathrm{T}_{1}\right)$ leading to collapse is about $0.248 \mathrm{~g}$ while the average PGA is about $0.859 \mathrm{~g}$. However, target drift $(0.04 \mathrm{rad})$ is achieved for lower values of spectral acceleration and PGA because of the high elastic displacement exhibited by the structure due to the pin-joint connection at the bottom of the first storey columns. Anyway, the collapse PGA is very high if compared with the design one $(0,2 \mathrm{~g})$ and it is considered always achieved when dissipative devices reach the target rotation equal to 0.04 rad being not observed unsatisfactory failure mechanism such as out of plane buckling of columns or the development of undesired mechanism of collapse. Finally, it important to observe that, although the structure exhibit low val- 
ues of the spectral acceleration at the collapse, dissipative devices have only achieved the device stroke and are even able to resort to other ductility resources such as the yielding of bolt in shear.

\section{CONCLUSIONS}

- In this work reference is made to pin-jointed MR-Frames with beam-to-column connections equipped with frictional devices.

- The control of devices activation and, as a consequence, the optimization of energy dissipation capacity is obtained by a rigorous design procedure assuring that only the dissipative zones are involved in plastic range while non dissipative ones remain elastic called Theory of Plastic Mechanism Control (TPMC)

- Thanks to the TPMC and being traditional dissipative zones substituted by frictional devices, column bases pin jointed and column sections designed in order to remain in elastic range, the structure can be considered as free from damage.

- By designing dissipative zones proportionally to the storey shear, they are assured to be engaged in yielding as contemporary as possible, benefit optimization of the seismic response.

- The accuracy of the design approach has been investigated by means push-over and nonlinear dynamic analyses by applying a properly chosen set of earthquake ground motions.

- The global mechanism is confirmed to be achieved by both push-over than IDA analyses.

- The designed structure show quite high performances that are, anyhow, compromised by the high structural displacement due to the pin-jointed column bases.

\section{REFERENCES}

[1] Mazzolani, F.M., Piluso, V., "Theory and Design of Seismic Resistant Steel Frames", E\&FN Spon, an imprint of Chapman \& Hall, 1996.

[2] EN 1998-1: "Eurocode 8: Design of Structures for Earthquake Resistance - Part 1: general Rules, Seismic Actions and Rules for Buildings", CEN, 2004

[3] Mazzolani, F.M., Piluso, V., "Plastic Design of Seismic Resistant Steel Frames", Earthquake Engineering and Structural Dynamics, Vol. 26, pp. 167-191, 1997.

[4] Montuori, R., Nastri, E., Piluso, V., "Advances in Theory of Plastic Mechanism Control: Closed Form Solution for Mr-Frames", Earthquake Engineering and Structural Dynamics, 2015.

[5] Montuori, R., Nastri, E., Piluso, V., "Theory of plastic mechanism control for MRFEBF dual systems: Closed Form Solution", Submitted for publication to Engineering Structures, 2016.

[6] Longo, A.; Montuori, R.; Piluso, V. Theory of Plastic Mechanism Control for MRFCBF dual system and its validation. Bulletin of Earthquake Engineering (BEEE). 2014.

[7] Giugliano M.T., Longo A., Montuori R., Piluso V. Failure mode and drift control of MRF-CBF dual systems The Open Construction and Building Technology Journal, 4, 121-133, 2010. 
[8] Montuori R., Piluso V., Troisi M. Theory of plastic mechanism control of seismicresistant MR-frames with set-backs. Open Construction and Building Technology Journal, vol. 6, pp. 404-413, 2012.

[9] Longo A., Montuori R., Piluso V., Theory of Plastic Mechanism Control of Dissipative Truss Moment Frames, Engineering Structures, Vol. 37, pp. 63-75, 2012.

[10] Longo A., Montuori R., Piluso V., Failure Mode Control and Seismic Response of Dissipative Truss Moment Frames, Journal of Structural Engineering, Vol. 138, pp.13881397, 2012.

[11] Longo A., Montuori, R., Nastri, E., Piluso, V. On the use of HSS in seismic-resistant structures Journal of Constructional Steel Research, Vol. 103, p. 1-12, 2014.

[12] Longo A., Montuori, R., Piluso, V., Moment Frames - Concentrically Braced Frames Dual Systems: Analysis of Different Design Criteria, Structure and infrastructure engineering, Volume 12, Issue 1, 2 January 2016, Pages 122-14.

[13] Longo A., Nastri E., Piluso V. Theory of plastic mechanism control: State-of-the-art. Open Construction and Building Technology Journal. Volume 8, 2014, Pages 262-278

[14] Longo A., Montuori R., Piluso V. Failure mode control of X-braced frames under seismic actions. Journal of Earthquake Engineering, 12: 728-759, 2008

[15] Longo A, Montuori R, Piluso V. Plastic design of seismic resistant V-Braced frames. Journal of Earthquake Engineering, vol. 12: 1246-1266, 2008.

[16] Longo A, Montuori R, Piluso V. "Influence of design Criteria on the seismic Reliability of X-Braced Frames", Journal of Earthquake Engineering, Vol. 12, Issue 3- p.406-431. 2008

[17] Montuori, R., Nastri, E., Piluso, V.,"Rigid-plastic analysis and moment-shear interaction for hierarchy criteria of inverted Y EB-Frames" Journal of Constructional Steel Research vol. 95 71-80. 2014.

[18] Montuori, R., Nastri, E., Piluso, V., Theory of Plastic Mechanism Control for Eccentrically Braced Frames with inverted Y-scheme, Journal of Constructional Steel Research, Volume 92, pp. 122-135, 2014.

[19] Giugliano M.T., Longo A., Montuori R., Piluso V., Plastic design of CB-frames with reduced section solution for bracing members. Journal of Constructional Steel Research. Vol. 66 pp 611-621. 2010.

[20] Longo A., Montuori R., Piluso V. Seismic reliability of V-braced frames: Influence of design methodologies. Earthquake Engineering and Structural Dynamics, vol. 38 p. 1587-1608, 2009.

[21] Longo A., Montuori R., Piluso V. Seismic Reliability of Chevron Braced Frames with Innovative Conception of Bracing Members, Advanced Steel Construction, an International Journal - Vol. 5, No. 4, December 2009.

[22] Montuori, R., Muscati, R. Plastic design of seismic resistant reinforced concrete frame. Earthquake and Structures Volume 8, Issue 1, 2015, Pages 205-224.

[23] Montuori, R. , Muscati, R. A General Procedure for Failure Mechanism Control of Reinforced Concrete Frames. Submitted for publication to Engineering Structures. 
[24] Castaldo P, Palazzo B, Della Vecchia P., "Seismic reliability of base-isolated structures with friction pendulum bearings", Engineering Structures, Vol. 95, 80-93, 2015

[25] Castaldo P, Tubaldi E., "Influence of FPS bearing properties on the seismic performance of base-isolated structures", Earthquake Engineering and Structural Dynamics 2015; Vol. 44, 2817-2836, 2015.

[26] Castaldo P., "Integrated Seismic Design of Structure and Control Systems", Springer International Publishing: New York, 2014. DOI 10.1007/978-3-319-02615-2, 2014.

[27] Castaldo P., De Iuliis M., "Optimal integrated seismic design of structural and viscoelastic bracing-damper systems", Earthquake Engineering and Structural Dynamics, Vol. 43(12),1809-1827, 2014.

[28] De Iuliis M., Castaldo P., "An energy-based approach to the seismic control of one-way asymmetrical structural systems using semi-active devices", Ingegneria Sismica - International Journal of Earthquake Engineering 2012; XXIX(4):31-42, 2012.

[29] Latour, M., Piluso, V., Rizzano, G. Free from damage beam-to-column joints: Testing and design of DST connections with friction pads. Engineering Structures. Volume 85, February 05, Pages 219-233, 2015.

[30] Montuori R., Nastri E., Piluso V. Theory of plastic mechanism control for the seismic design of braced frames equipped with friction dampers - Mechanics Research Communications - Vol. 58. pp. 112-123 2014.

[31] Montuori R., Piluso V., Troisi M. Innovative structural details in MR-frames for free from damage structures Mechanics Research Communications - Vol. 58 pp. 146-156. 2014.

[32] Lee S-S., Goel S.C., "Performance-Based Design of Steel Moment Frames using Target Drift and Yield Mechanism", Research Report UMCEE 01-17, University of Michigan, December 2011.

[33] Goel S.C., Chao S-H., "Performance-Based Plastic Design: Earthquake Resistant steel Structures", International Code Council: Washington, DC, 2008.

[34] Latour M., Rizzano G., Piluso V. (2012): “Experimental Analysis of Innovative Dissipative Bolted Double Split Tee Beam-to-Column Connections", Steel Construction, 4 (2011), N.2, 53-64.

[35] Latour M., Piluso V., Rizzano G. (2014), "Experimental analysis on friction materials for supplemental damping devices", Construction and Building Materials, Volume 65, 29 August 2014, 159-176.

[36] CSI 2007. SAP 2000: Integrated Finite Element Analysis and Design of Structures. Analysis Reference. Computer and Structure Inc. University of California, Berkeley.

[37] Pacific Earthquake Engineering Research Center, PEER Strong Motion Database, http://peer.berkley.edu.smcat. 